ИЗВЕСТИЯ АКАДЕМИИ НАУК ЭСТОНСКОП ССР. ТОМ 27

ХИМИЯ. 1978, № 3

Хелье УРБЕЛЬ

удК $547.262 ; 661.185$

\title{
КОНДЕНСАЦИЯ ФЕНИЛАЛКАНОВ ОКИСЬЮ ЭТИЛЕНА В ПРИСУТСТВИИ КИСЛОТ ЛЬЮИСА
}

Окись этилена в присутствии кислот Льюиса реагирует с ароматическими углеводородами с образованием спиртов [ $\left.{ }^{1-4}\right]$. По литературным данным, конденсация окиси этилена с бензолом и его гомологами изучена, главным образом, в случае применения безводного $\mathrm{AlCl}_{3}$ [ $\left.{ }^{5}\right]$. При замене $\mathrm{AlCl}_{3}$ на $\mathrm{SnCl}_{4}$, по мнению Ж. Колонже, реакция не идет [6]. В качестве катализатора были испытаны также $\mathrm{ZnCl}_{2}, \mathrm{FeCl}_{3}, \mathrm{BF}_{3}$ и $\mathrm{HF}$. Из них первые три не имеют каких-либо преимуществ перед $\mathrm{AlCl}_{3}\left[{ }^{7}\right]$.

Нами исследовалась реакция конденсации окиси этилена фенилалканами $\mathrm{C}_{6}-\mathrm{C}_{10}$ в присутствии следующих кислот Льюиса: $\mathrm{BF}_{3}$, $\mathrm{BF}_{3} \cdot \mathrm{H}_{3} \mathrm{PO}_{4}, \mathrm{BF}_{3} \cdot \mathrm{H}_{2} \mathrm{SO}_{4}, \mathrm{ZnCl}_{2}, \mathrm{FeCl}_{3}, \mathrm{TiCl}_{4}, \mathrm{SnCl}_{4}, \mathrm{AlCl}_{3}$, а также моногидрата серной кислоты и $35,8 \%$-ного олеума.

Согласно $\left[{ }^{5,7}\right]$, образование ароматических спиртов в присутствии $\mathrm{AlCl}_{3}$ происходит следующим образом:

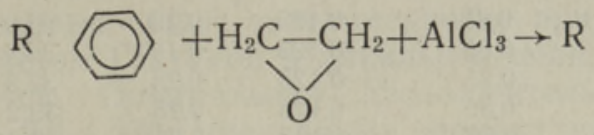

$\mathrm{R}$ $\downarrow \mathrm{H}_{2} \mathrm{O}$

$\bigcirc \mathrm{CH}_{2} \mathrm{CH}_{2} \mathrm{OH}+\mathrm{AlOHCl}_{2}$

Удалось установить, что при конденсации ароматического ядра и окиси этилена в присутствии $\mathrm{SnCl}_{4}$ дозировка двукратного молекулярного количества окиси этилена (по отношению к катализатору) приводит к двукратному увеличению выхода целевых алкилфенилэтиловых спиртов (АФЭС). При использовании в качестве катализатора $\mathrm{TiCl}_{4}$ выход АФЭС повышается только примерно на $25 \%$, хотя механизм катализа, очевидно, одинаков и в том и в другом случаях. При применении катализатора $\mathrm{AlCl}_{3}$ двойное молярное количество окиси этилена, наоборот, снижает выход АФЭС почти на 20\%. При этом важно, что если образование комплекса с $\mathrm{AlCl}_{3}$ (реакция 1) сопровождается выделением $\mathrm{HCl}$, то при катализаторах $\mathrm{SnCl}_{4}$ и $\mathrm{TiCl}_{4} \mathrm{HCl}$ не выделяется, а образуется комплексная кислота с $\mathrm{SnCl}_{4}$ и $\mathrm{TiCl}_{4}$ (реакция 6).

По мнению автора, конденсация протекает по следующей схеме:

$\mathrm{R}$<smiles>[R]C(C)CC1CO1</smiles> 
таблица 1

\section{Конденсация фенилалканов окисью этилена в присутствии $\mathrm{SnCl}_{4}, \mathrm{TiCl}_{4}$ и $\mathrm{AlCl}_{3}$}

\begin{tabular}{|c|c|c|c|c|c|c|c|}
\hline \multirow{3}{*}{ 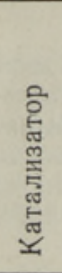 } & \multirow{3}{*}{$\begin{array}{c}\text { Исходный } \\
\text { фенилалкан }\end{array}$} & \multicolumn{5}{|c|}{ Условия синтеза } & \multirow{3}{*}{ 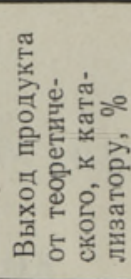 } \\
\hline & & \multirow{2}{*}{ 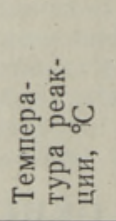 } & \multirow{2}{*}{ 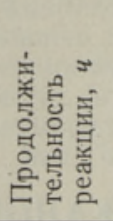 } & \multicolumn{3}{|c|}{$\begin{array}{c}\text { Количество исходных } \\
\text { веществ, } 2 \cdot \text { моль }\end{array}$} & \\
\hline & & & & 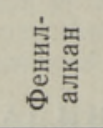 & 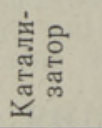 & 导农 & \\
\hline \multirow{5}{*}{ 式 } & фенилгексан & $\begin{array}{c}23-24 \\
25-26 \\
25 \\
25-26 \\
25-26\end{array}$ & $\begin{array}{l}2,0 \\
1,8 \\
2,2 \\
1,0 \\
3,0\end{array}$ & $\begin{array}{l}0,25 \\
0,25 \\
0,50 \\
0,50 \\
0,50\end{array}$ & $\begin{array}{l}0,125 \\
0,125 \\
0,125 \\
0,125 \\
0,125\end{array}$ & $\begin{array}{l}0,25 \\
0,25 \\
0,25 \\
0,25 \\
0,375\end{array}$ & $\begin{array}{l}70,3 \\
82,8 \\
81,7 \\
67,4 \\
90,4\end{array}$ \\
\hline & фенилгептан & $\begin{array}{c}0 \\
15 \\
20 \\
25 \\
35-37 \\
25 \\
25 \\
25\end{array}$ & $\begin{array}{l}1,0 \\
1,0 \\
1,0 \\
1,0 \\
1,5 \\
1,8 \\
2,0 \\
2,0\end{array}$ & $\begin{array}{l}0,25 \\
0,25 \\
0,25 \\
0,25 \\
0,25 \\
0,25 \\
0,25 \\
0,50\end{array}$ & $\begin{array}{l}0,125 \\
0,125 \\
0,125 \\
0,125 \\
0,125 \\
0,125 \\
0,125 \\
0,25\end{array}$ & $\begin{array}{l}0,137 \\
0,137 \\
0,137 \\
0,137 \\
0,137 \\
0,137 \\
0,25 \\
0,50\end{array}$ & $\begin{array}{l}11,9 \\
37,7 \\
44,3 \\
46,2 \\
37,4 \\
48,5 \\
83,4 \\
91,9\end{array}$ \\
\hline & фенилоктан & $25-26$ & $\begin{array}{l}2,0 \\
1,8\end{array}$ & $\begin{array}{l}0,25 \\
0,25\end{array}$ & $\begin{array}{l}0,125 \\
0,125\end{array}$ & $\begin{array}{l}0,25 \\
0,25\end{array}$ & $\begin{array}{l}68,5 \\
55,2\end{array}$ \\
\hline & фенилнонан & 30 & 2,2 & 0,25 & 0,125 & 0,25 & 63,0 \\
\hline & фенилдекан & 35 & 1,8 & 0,25 & 0,125 & 0,25 & 61,1 \\
\hline \multirow{5}{*}{$\dot{\bar{j}}$} & фенилгексан & $\begin{array}{c}14-15 \\
20 \\
20 \\
20 \\
20 \\
20\end{array}$ & $\begin{array}{l}2,0 \\
1,8 \\
2,2 \\
1,1 \\
2,0 \\
3,0\end{array}$ & $\begin{array}{l}0,25 \\
0,25 \\
0,25 \\
0,50 \\
0,50 \\
0,50\end{array}$ & $\begin{array}{l}0,125 \\
0,125 \\
0,125 \\
0,125 \\
0,125 \\
0,125\end{array}$ & $\begin{array}{l}0,25 \\
0,137 \\
0,25 \\
0,25 \\
0,25 \\
0,375\end{array}$ & $\begin{array}{l}26,6 \\
26,4 \\
32,3 \\
39,2 \\
49,2 \\
49,3\end{array}$ \\
\hline & фенилгептан & $\begin{array}{l}20 \\
25 \\
25\end{array}$ & $\begin{array}{l}2,0 \\
2,2 \\
2,0\end{array}$ & $\begin{array}{l}0,25 \\
0,25 \\
0,50\end{array}$ & $\begin{array}{l}0,125 \\
0,125 \\
0,125\end{array}$ & $\begin{array}{l}0,25 \\
0,25 \\
0,25\end{array}$ & $\begin{array}{l}29,7 \\
33,2 \\
39,2\end{array}$ \\
\hline & фенилоктан & $\begin{array}{c}25 \\
30 \\
25-27\end{array}$ & $\begin{array}{l}2,2 \\
2,2 \\
2,2\end{array}$ & $\begin{array}{l}0,25 \\
0,25 \\
0,50\end{array}$ & $\begin{array}{l}0,125 \\
0,125 \\
0,125\end{array}$ & $\begin{array}{l}0,25 \\
0,25 \\
0,25\end{array}$ & $\begin{array}{l}21,5 \\
21,8 \\
32,3\end{array}$ \\
\hline & фенилнонан & $\begin{array}{l}30 \\
30\end{array}$ & $\begin{array}{l}2,0 \\
2,3\end{array}$ & $\begin{array}{l}0,25 \\
0,50\end{array}$ & $\begin{array}{l}0,125 \\
0,125\end{array}$ & $\begin{array}{l}0,25 \\
0,25\end{array}$ & $\begin{array}{l}24,6 \\
31,2\end{array}$ \\
\hline & фенилдекан & $\begin{array}{l}30 \\
30\end{array}$ & $\begin{array}{l}2,0 \\
2,3\end{array}$ & $\begin{array}{l}0,25 \\
0,50\end{array}$ & $\begin{array}{l}0,125 \\
0,125\end{array}$ & $\begin{array}{l}0,25 \\
0,25\end{array}$ & $\begin{array}{l}20,7 \\
30,3\end{array}$ \\
\hline \multirow{5}{*}{$\frac{\infty}{\square}$} & фенилгексан & $\begin{array}{l}\frac{-5}{-5} \\
-5-0 \\
-5 \\
-5-0\end{array}$ & $\begin{array}{l}1,6 \\
4,5 \\
1,0 \\
2,0 \\
2,0\end{array}$ & $\begin{array}{l}0,70 \\
3,50 \\
0,30 \\
0,60 \\
1,50\end{array}$ & $\begin{array}{l}0,35 \\
1,75 \\
0,10 \\
0,20 \\
0,75\end{array}$ & $\begin{array}{l}0,39 \\
1,93 \\
0,11 \\
0,22 \\
0,83\end{array}$ & $\begin{array}{l}50,7 \\
52,1 \\
60,7 \\
71,2 \\
54,0\end{array}$ \\
\hline & фенилгептан & $\begin{array}{l}0 \\
0 \\
0\end{array}$ & $\begin{array}{l}2,0 \\
2,0 \\
1,8\end{array}$ & $\begin{array}{l}1,60 \\
1,20 \\
0,50\end{array}$ & $\begin{array}{l}0,80 \\
0,40 \\
0,25\end{array}$ & $\begin{array}{l}0,88 \\
0,44 \\
0,50\end{array}$ & $\begin{array}{l}56,9 \\
61,8 \\
47,7\end{array}$ \\
\hline & фенилоктан & 0 & 3,5 & 3,3 & 1,65 & 1,82 & 51,5 \\
\hline & фенилнонан & 5 & 3,5 & 0,9 & 0,60 & 0,66 & 49,2 \\
\hline & фенилдекан & 5 & 2,0 & 1,0 & 0,50 & 0,55 & 47,9 \\
\hline
\end{tabular}




\section{$\mathrm{R}$ (O) $\mathrm{CH}_{2} \mathrm{CH}_{2} \mathrm{OMeCl}_{3}+\underbrace{\mathrm{H}}_{\mathrm{O}}-\mathrm{CH}_{2}+$ (O) $\mathrm{R} \rightarrow$<smiles>CPc1ccc(CCC(Cl)(OCc2ccc(Cl)cc2)[AlH2]O)cc1</smiles>

?R (O) $\mathrm{CH}_{2} \mathrm{CH}_{2} \mathrm{OH}+\mathrm{Me}(\mathrm{OH})_{2} \mathrm{Cl}_{2}$

$\mathrm{MeCl}_{4}+2 \mathrm{HCl} \rightarrow \mathrm{H}_{2}\left[\mathrm{MeCl}_{6}\right]$, где $\mathrm{Me}--\mathrm{Sn}$ нли Ti

\section{Результаты экспериментов и их обсуждение}

Конденсация фенилалканов и окиси этилена проводится в колбе, снабженной мешалкой, термометром и трубкой для барботирования. Пары окиси этилена в смеси с азотом ( $1: 5$ по объему) пропускают через раствор фенилалкана и катализатора при энергичном перемешивании последних. Полученный растворенный в фенилалкане комплекс гидролизуют ледяной водой. После многократного промывания водой реакционная смесь высушивается [5]. Выходы АФЭС вычисляются по гидроксильному числу.

Условия и результаты опытов приведены в табл. 1 и 2. Выяснились некоторые общие закономерности при катализе с $\mathrm{SnCl}_{4}, \mathrm{TiCl}_{4}$ и $\mathrm{AlCl}_{3}$. С ростом С-атомов в алкильной цепи фенилалканов выход АФЭС снижается. Оптимальная продолжительность реакции - в пределах $1,5-2,0$ ч. При уменьшении времени реакции до 1 ч выход АФЭС снижается на $10-30 \%$. Увеличение продолжительности реакции (более 2 и) на выход АФЭС не влияет. Повышение молярного соотношения фенилалкана и окиси этилена от $2: 1$ до $3: 1$ или $4: 1$ при катализе с $\mathrm{TiCl}_{4}$ и $\mathrm{AlCl}_{3}$ увеличивает выход АФЭС на $10-30 \%$.

Условия реакции при катализе с $\mathrm{SnCl}_{4}$ и $\mathrm{TiCl}_{4}$ другие, чем с $\mathrm{AlCl}_{3}$. Жидкие $\mathrm{SnCl}_{4}$ и $\mathrm{TiCl}_{4}$ хорошо растворяются в фенилалканах, обладая, таким образом, преимуществом перед малорастворимым порошкообразным $\mathrm{AlCl}_{3}$. Оптимальная температура реакции при $\mathrm{SnCl}_{4}$ и $\mathrm{TiCl}_{4}-20-30^{\circ} \mathrm{C}$, при $\mathrm{AlCl}_{3}-5-10^{\circ}$. С увеличением молярного соотношения окиси этилена и $\mathrm{SnCl}_{4}$ от $1,1: 1$ до $2: 1$ выход АФЭС повышается на $70-90 \%$. Трехкратное увеличение молярного количества окиси этилена при $\mathrm{SnCl}_{4}$ повышает выход АФЭС еще на $10 \%$, при $\mathrm{TiCl}_{4}$ выход практически не изменяется.

Таблица 2

\section{Оптимальные условия синтеза гептилфенилэтиловых спиртов при молярном соотношении гептилбензола и окиси этилена с катализатором 2:1}

\begin{tabular}{|c|c|c|c|}
\hline Катализатор & 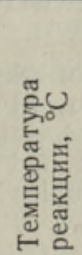 & 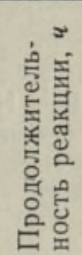 & 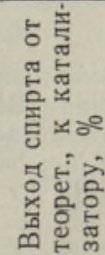 \\
\hline
\end{tabular}

$\begin{array}{lrll}\mathrm{SnCl}_{4} & 25 & 2,0 & 91,9 \\ \mathrm{AlCl}_{3} & 0 & 1,8 & 47,7 \\ \mathrm{TiCl}_{4} & 25 & 2,2 & 33,2\end{array}$


Таким образом, при замене хлористого алюминия хлорным оловом можно увеличить выход АФЭС на $25-60 \%$. TiCl 4 уступает $\mathrm{SnCl}_{4}$ и $\mathrm{AlCl}_{3}$.

Для изучения конденсации с остальными указанными выше катализаторами опыты проводились в диапазоне температур $0-100^{\circ}$ с интервалами в $10^{\circ}$, продолжительность реакции $-0,4-2,0$ ч. При катализе с моногидратом серной кислоты и олеумом реакция не протекала, с остальными катализаторами были получены выходы АФЭС порядка $1-4 \%$.

\section{ЛИТ Е Р А Т Р Р А}

1. М а лин о в ски й М. С. Окиси олефинов и их производные. М., 1961, с. 354.

2. In a tsug i, T. Phenylethyl alcohol. - Chem. Abstrs, 1950, v. 44, p. 3937.

3. Пат. Канады 340555. - Chem. Abstrs, 1934, v. 28, p. 4067; Пат. США 204396. Chem. Abstrs, 1936 , v. 30 , p. 6005.

4. Шорыгина Н. В. К вопросу о конденсации окиси этилена с гомологами бензола. - ЖОХ, 1951, т. 21, с. 1273-1275.

5. Ф ай нгольд С., Йе р с Я. Алкилфенилэтиловые спирты и поверхностно-активные вещества (ПАВ) на их основе. - Изв. АН ЭССР, хим., геол., 1973, т. 22, № 2, c. $108-112$.

6. Colongé, J., Roch a s, P. Reaction of ethylene oxide with aromatic hydrocarbons in the presence of aluminium chloride. - Chem. Abstrs, 1949, v. 43, p. 2181.

7. Calcott, W., Tinker, J., Weinmayr, V. Hydrofluoric acid as a condensing agent. II. Nuclear alkylations in the presence of hydrofluoric acid. - J. Amer. Chem. Soc., 1939 , v. 61 , p. $10,10$.

Ннститут химии
Академии наук Эстонской ССР

Поступила. в редакцию 24/VI 1977

Helje URBEL

\section{ALKUOLBENSOOLIDE JA ETULEENOKSIIDI KONDEN- SATSIOON LEWISI HAPETE TOIMEL}

Artiklis on käsitletud alküülbensoolide ja etüleenoksiidi kondensatsiooni Lewisi hapete $\mathrm{BF}_{3}, \mathrm{BF}_{3} \cdot \mathrm{H}_{3} \mathrm{PO}_{4}, \mathrm{BF}_{3} \cdot \mathrm{H}_{2} \mathrm{SO}_{4}, \mathrm{ZnCI}_{2}, \mathrm{FeCl}_{3}, \mathrm{TiCl}_{4}, \mathrm{SnCl}_{4}$ ja $\mathrm{AlCl}_{3}$ toimel. On selgitatud optimaalsed katalüüsitingimused $\mathrm{SnCl}_{4}$ ja TiCl$_{4}$ kasutamise korral ja tehtud kindlaks, et etüleenoksiidi kahekordne moolhulk katalüsaatori suhtes kahekordistab alküülfenüületüülalkoholide saagist.

Helje URBEL

\section{CONDENSATION OF ALKYLBENZENES WITH ETHYLENE OXIDE IN THE PRESENCE OF LEWIS ACIDS}

Condensation reaction of alkylbenzene with ethylene oxide in the presence of some Lewis acids $\left(\mathrm{BF}_{3}, \mathrm{BF}_{3} \cdot \mathrm{H}_{3} \mathrm{PO}_{4}, \mathrm{BF}_{3} \cdot \mathrm{H}_{2} \mathrm{SO}_{4}, \mathrm{ZnCl}_{2}, \mathrm{FeCl}_{3}, \mathrm{TiCl}_{4}, \mathrm{SnCl}_{4}\right.$ and $\left.\mathrm{AlCl}_{3}\right)$ has been investigated. Optimal conditions of catalysis with $\mathrm{SnCl}_{4}$ and $\mathrm{TiCl}_{4}$ have been presented. It has been determined that in the presence of $\mathrm{SnCl}_{4}$ the double mole ratio of ethylene oxide to catalyst redoubles the yield of alkylphenylethanols. 